\title{
Regional Governance of Syndromic Surveillance for the Texas Gulf Coast
}

\author{
Wesley McNeely, Eunice R. Santos, Biru Yang, Kiley Allred and Raouf R. Arafat \\ OSPHP, Houston Health Department, Houston, TX, USA
}

\section{Objective}

Describe and explain the transition of the syndromic surveillance program at the Houston Health Department (HHD) from being a locally managed and aging system to an ESSENCE system governed by a regional Consortium of public health agencies and stakeholders in the 13-county area of the southeast Texas.

\section{Introduction}

Syndromic surveillance systems are large and complex technology projects that increasingly require large investments of financial and political capital to be sustainable. What was once a minor surveillance tool in the mid-2000s has evolved into a program that is regarded as valuable to public health yet is increasingly difficult to maintain and operate for local health departments. The Houston Health Department installed a syndromic surveillance system (SyS) six years before Meaning Use became known to healthcare communities. The system chosen at the time was the Real-time Outbreak Disease Surveillance System (RODS) which, at the time and for its purpose, was a suitable platform for syndromic surveillance. During the past 13 years however, maintaining, operating, and growing a SyS by a local health department has become increasingly difficult. Inclusion in Meaningful Use elevated the importance and profile of syndromic surveillance such that network growth, transparency of operations, ease of data sharing, and cooperation with other state systems in Texas became program imperatives.

\section{Methods}

With support from the informatics group at Tarrant County Public Health (TCPH) in the form of mentoring, HHD devised a two prong strategy to re-invigorate the syndromic program. The first was to replace RODS with ESSENCE from Johns Hopkins Applied Physics Laboratory (JH/APL). The second was to strengthen the regional network by creating a governance structure that included outside agencies and stakeholders. The product of this second effort was the creation of the Syndromic Surveillance Consortium of Southeast Texas (SSCSeT) on the Communities of Practice model ${ }^{1}$ using parliamentary procedure ${ }^{2}$.

\section{Results}

Acquiring ESSENCE and forming SSCSeT were necessary steps for the continuing operation of the SyS. The Consortium includes members from local health jurisdictions, health care providers, health policy advocates, academicians, and data aggregators. Created as a democratic society, SSCSeT wrote its constitution and by-laws, voted in officers, formed working groups and has begun developing policies. The Consortium is cooperating with the Texas Department of State Health Services (DSHS) as well as TCPH. Having ESSENCE will ensure the HHD-SyS will conform to standards being developed in the state and provide a robust syndromic platform for the partners of the Consortium.

\section{Conclusions}

Syndromic systems operated by local health departments can adapt to regulatory changes by growing their networks and engaging regional stakeholders using the Communities of Practice model.

\section{Keywords}

Communities of Practice; Texas; Gulf Coast; Syndromic Surveillance

\section{Acknowledgments}

The authors would like to acknowledge the support of Bill Stephens and Dave Heinbaugh of Tarrant County Public Health and members of the Syndromic Surveillance Consortium of Southeast Texas from the following jurisdictions:

-Beaumont Public Health Department

-Brazoria County Health Department

- Fort Bend County Department of Health and Human Services

- Galveston County Health District

- Harris County Public Health and Environmental Services

- Houston Health Department

-Montgomery County Public Health District

- Port Arthur Health Department

-Texas Department of State Health Services Region 6/5 South

\section{References}

1 Wenger, Etienne, McDermott, Richard, Snyder, William M. Cultivating Communities of Practice. Harvard Business School Press. Boston, MA. 2002.

2. Robert, Henry M,.et al., Robert's Rules of Order Newly Revised (11th ed.). Philadelphia, PA, Da Capo Press, 2011.

\section{*Wesley McNeely}

E-mail: wesley.mcneely@houstontx.gov 